\title{
Ocho casos de violencia contra la mujer en el discurso periodístico peruano
}

\section{Eight Instances of Violence Against women In Peruvian Journalistic Discourse}

Pusaq warmi llakichinamanta willasqakuna perú suyupa qillqasqa rapran nisqanpi

\section{Luisa Portilla Durand ${ }^{1}$}

Universidad Nacional Mayor de San Marcos, Lima, Perú castellanodelima@hotmail.com

\section{RESUMEN}

Se presenta una muestra del análisis del discurso periodístico peruano que trata acerca de la violencia contra la mujer, en particular en el caso de feminicidio o intento de feminicidio.

Del corpus, recopilado de los diarios de circulación nacional en el Perú, se presenta en esta oportunidad una selección de casos de violencia contra la mujer ocurridos en agosto de 2015, ocho casos en los que se explicitó el nombre de víctimas y victimarios.

A partir de la selección, se identifican y analizan las estructuras discursivas con las que algunos medios de comunicación peruanos visibilizan o, por el contrario, justifican la violencia contra la mujer.

\section{PALABRAS CLAVE}

Violencia contra la mujer, feminicidio, discurso periodístico, estructuras discursivas, medios de comunicación

1 Licenciada en Lingüística, magíster en Educación con la mención Docencia en el Nivel Superior, con estudios concluidos de doctorado en Literatura Peruana y Latinoamericana. Catedrática principal de la Facultad de Letras de la Universidad Nacional Mayor de San Marcos. Investigadora miembro A del Instituto de Investigaciones Lingüísticas de la Universidad Nacional Mayor de San Marcos. Becaria de la Real Academia Española en 2002 y de 2008 a 2010. Ha participado como ponente en diversos eventos nacionales e internacionales. Es autora de artículos y libros relacionados con la normativa y la lexicografía en español. El 7 de mayo de 2012 recibió el Premio al Mérito Científico por parte del Vicerrectorado de Investigación de la Universidad Nacional Mayor de San Marcos. 


\section{ABSTRACT}

A sample is presented of Peruvian journalistic discourse analysis which deals with violence against women, particularly in the cases of femicide or attempted femicide.

Out of the corpus, compiled from newspapers in Peru, this paper presents a selection of eight cases of violence against women that took place in August 2015, in which the names of victims and perpetrators were disclosed.

From the selection, discourse structures are identified and analyzed that are used by some Peruvian newspapers and TV channels which can either make violence against women visible or, on the contrary, justify that violence.

\section{KEYWORDS}

Violence against women, femicide, journalistic discourse, mass media

\section{PISILLAPI QILLQASQA}

Kay qillqasqaqa riqsichinqa huk patmata qillqasqa rapra nisqanmanta, chay ima nisqanmanta warmita llakichiykunamanta. Aswantaqmi rimanqa chay imanasqan, imaraykun warmitaqa takanku, qaqtanku, sipinku runakunaqa. Perú suyupi imatan niraku killachikuqkuna iskay waranqa pichqa chunka watapiqa, chaymantapunin rimanqa kay qillqasqaqa. Chaypaqmi akllasun pusaq wirmi llakichisqata. Chayna ruwasqakunaqa wakin willachikuqkunapaqa allinsi kara, wakinpaqtaq manapuni allinchu, warmita ima llakipi tiyachiyta, warmitaqa manas maqanachu.

\section{TIQSI RIMANAKUNA}

Warmi Ilaquichiy, warmi sipiy, qillqasqa raprapa nisqankuna, willachikuqkuna

A Adrián Emilio Limachi Chancahuana, taxista ayacuchano que ha quedado parapléjico después de haber intentado defender a una mujer que estaba siendo agredida por un hombre.

\section{Algunos antecedentes}

Miguel Lorente (2001, p. 27) señala: «La estructura androcéntrica y los valores patriarcales han hecho [...] que la agresión a la mujer haya sido aceptada como algo normal y consecuente con la función de autoridad del hombre, por lo cual en la mayoría de las ocasiones ni siquiera se ha considerado, y en las pocas que se ha hecho ha sido interpretada y justificada desde la perspectiva del hombre». 
Por su parte, Natalia Fernández (2003, p. 7) sostiene: «Los medios manejan las representaciones mentales y lo hacen mediante el control de creencias, conocimientos y estereotipos, por una parte, y facilitando el acceso a voces autorizadas, por otra». En cuanto al estudio de Fernández, debo explicitar que su investigación se basa en el análisis de noticias publicadas en siete diarios españoles (1989-1994) en los que se exponen, fundamentalmente, casos de violación sexual contra mujeres. En el presente estudio, en el que se muestran ocho casos de violencia contra la mujer, se analiza el discurso periodístico peruano de los diarios limeños que tratan acerca de la violencia contra la mujer, en particular en el caso de feminicidio o intento de feminicidio en agosto de 2015. (El tamaño de la muestra se debe a las limitaciones de espacio propias de un artículo de investigación y a que solo en ocho casos se explicitaron los nombres de víctimas y victimarios).

En la presentación del libro La violencia contra la mujer: feminicidio en el Perú (2005), elaborado por el Centro de la Mujer Peruana Flora Tristán, se afirma lo siguiente: «La violencia ejercida contra la mujer es un problema que obedece a estructuras jerárquicas patriarcales que reproducen una cultura donde las mujeres son vistas como objetos desechables y maltratables» (p. 7). Y acerca del feminicidio se sostiene: «El feminicidio es una categoría que debe abordarse como la forma más extrema e irreparable de violencia directa hacia las mujeres. [...] El feminicidio es un crimen que debe ser atendido por el Estado. No tiene actores ni coyunturas únicas, ni tampoco existe un perfil único de víctimas» (p. 7).

Miguel Ángel Ramos (2006, p. 129) indica que los «hombres recusan, por diversos motivos, la utilización de la violencia física o sexual contra la mujer. Cuando se les preguntó cómo catalogaban sus relaciones de pareja, la mayoría de ellos adujo que estas eran buenas y armónicas. Sin embargo, en todos estos casos se percibe claramente que el ejercicio del poder masculino es casi absoluto y la hegemonía de las relaciones jerárquicas y autoritarias es abrumadora».

Acerca del poder como agente de control del discurso público, Teun A. van Dijk (2009, p. 36) señala que «el control del discurso público implica el control de la mente del público y, por consiguiente, indirectamente, el control de lo que el público quiere y hace. No hace falta la coerción si uno puede persuadir, seducir, adoctrinar o manipular al pueblo».

Respecto de la segregación por el género, Guillermo Nugent (2010, pp. 66-67) sostiene: «Nada más intemporal que sostener la segregación por el género, pues se trata de una diferencia de nacimiento, previa a cualquier historia, por decirlo así. Aparte de la abrumadora misoginia que respalda este tipo de actitudes, hay una derivación de parecida importancia: 
sostener que hay una diferencia entre los seres humanos que viene desde el nacimiento, previa a cualquier interacción. Se trata de una suerte de ecumenismo perverso según el cual en todas las sociedades y en todas partes siempre va a haber esa diferencia fundamental entre hombres y mujeres que tendrá fuerza de orden cósmico, donde las segundas están destinadas a los trabajos de reproducción y colaterales, y los primeros a las tareas de gobierno, como en cierto modo la propia estructura del Vaticano lo testimonia».

Por otro lado, Diana Valle (2011, pp. 14-15) señala que «las investigaciones y los estudios de prevalencia e incidencia realizados por Gelles y Straus (1979) los llevaron a afirmar que "es más probable que una persona sea asesinada, atacada físicamente, golpeada, abofeteada o azotada en su propio hogar por otro miembro de la familia que en cualquier otro lugar o por cualquier otra persona en nuestra sociedad". Además, aseguran que la institución de la familia es la más violenta en nuestra sociedad con excepción del aparato militar en tiempos de guerra. Para Marcela Lagarde (2006, p. 284), "el matrimonio y la familia son instituciones totales, pertenecen a la clase de instituciones como la cárcel y el manicomio en que los individuos se encuentran solos y a merced del poder del hombre, inermes y en absoluta desigualdad". [...] Schecter (1982) argumenta que ningún evento de maltrato debe considerarse como simple o aislado, pues aun en el caso de una mujer que es golpeada solamente una vez, esto le enseña una "lección" sobre quién controla la relación y cómo este control será utilizado en el futuro».

A su vez, Óscar Santini (2013, p. 11) afirma: «Ante el avance en la autonomía y el reconocimiento de sus derechos por parte de las mujeres, algunos varones quedan con la presión del mandato de género desconociendo su lugar y el de la mujer en relación simétrica. Para restablecer la asimetría, ejerce violencia como supuesto modo de recuperar poder; así aparecen los celos como catalizadores de la violencia, o cuando la mujer se niega a tener relaciones sexuales o cuando siente temor o riesgo de perder el control de la relación por el avance en la autonomía de "su" mujer en carácter de propiedad».

Asimismo, Carlos Fidel y otros (2014, p. 14) señalan que «la violencia contra las mujeres es la forma más extensa en el tiempo y el espacio de una forma de violencia perpetrada contra una persona por su condición de género $y$, tal como lo han señalado numerosos estudios, la violencia contra las mujeres constituye una forma de violencia social estructural».

En el informe emitido en el Perú por el Instituto Nacional de Estadística (INEl, 2014, p. 36) se indica que el feminicidio es «el episodio final en una cadena de violencia y discriminación contra la mujer». Asimismo, se 
señala que la violencia feminicida es la forma extrema de violencia contra las mujeres.

\section{Muestra}

\section{CASO 1}

Agresor: Luis Ángel Piscoya Pérez (30)

Víctima: Misui Rosalía Chávez Sandoval (26)

1. Sobretitular: Pese a brutal agresión en Piura, salvaje fue dejado en libertad y ahora está como no habido

Titular: Sujeto armado golpea, desnuda y arrastra a su pareja en hotel

Subtitulares: Víctima lo denunció en 2014 por el mismo delito / Tras escándalo fiscal solicitó prisión preventiva

El Popular, 6 de agosto de 2015, p. 4

\section{Comentario}

Obsérvese que en la noticia se toma parte por la víctima a través del uso de las siguientes expresiones: «brutal agresión», «salvaje fue dejado en libertad», «sujeto armado golpea, desnuda y arrastra». A la agresión se la califica de brutal, el agente de la «brutal agresión» es calificado como salvaje; el sujeto (no se le identifica) «armado golpea, desnuda y arrastra a su pareja» (no se explicita el tipo de relación).

Por otra parte, nótese que la palabra sujeto («persona cuyo nombre se ignora o no se quiere decir») es imprecisa, genera indeterminación respecto del agente de la «brutal agresión». Aunque en el cuerpo de la noticia se usa la palabra el agresor y figura su nombre: Luis Ángel Piscoya Pérez (30) / Luis Piscoya.

También es imprecisa la palabra pareja («compañero o compañera del sexo opuesto»). De acuerdo con el cuerpo de la noticia, la víctima, Misui Rosalía Chávez Sandoval, era conviviente del agresor y tiene dos hijos con él.

Se manifiesta, pues, una postura ambivalente respecto del hecho de violencia: visibilización/invisibilización.

2. Sobretitular: Familiares desconocen paradero de Misui desde el martes

Titular: Temen por la vida de joven masacrada en local de Piura

Subtitular: Creen que esté en manos de agresor, quien estuvo recluido en penal de Río Seco

El Popular, 7 de agosto de 2015, p. 3

\section{Comentario}

Nótese que en esta noticia se expone el discurso haciendo referencia a terceras personas (los familiares), con lo que se distancia el hecho de 
agresión: «desconocen paradero de Misui», «Temen por la vida de joven masacrada», «Creen que esté en manos de agresor».

En cuanto a la selección léxica, se visibiliza el hecho de la agresión a través de las expresiones joven masacrada y en manos del agresor.

No obstante, la palabra joven («que está en la juventud») y agresor («que comete agresión») son imprecisas (sobre todo la primera), ya que la víctima y su agresor tienen nombre propio, los cuales se citan en el cuerpo de la noticia: Misui Rosalía Chávez Sandoval y Luis Ángel Piscoya Pérez, respectivamente.

En este caso también se observa una postura ambivalente respecto del hecho de violencia: visibilización/invisibilización.

3. Sobretitular: Ministra de la Mujer pide revocar comparecencia y que Luis Ángel Piscoya vaya a la cárcel

Titular: Indignación por fallo favorable para sujeto que masacró a Misui

Subtitulares: Titular de Justicia opina que agresor «se burla de la justicia» / Polémica resolución ya fue apelada

El Popular, 19 de agosto de 2015, p. 4

\section{Comentario}

Nótese que en la noticia se destaca lo considerado por las autoridades que imparten justicia y, de esta manera, se toma parte por la víctima: «Ministra de la Mujer pide [...]» y «Titular de Justicia opina [...]». Asimismo, se explicita el nombre y apellido del agresor Luis Ángel Piscoya.

4. Sobretitular: Autoridades piden que decisión sea rectificada

Titular: Rechazo e indignación ante fallo de jueza que da libertad a agresor de mujer

Exitosa, 19 de agosto de 2015, p. 13

\section{Comentario}

Nótese que en esta noticia, como en la anterior, se destaca lo considerado por las autoridades que imparten justicia. Por otra parte, a diferencia de las noticias anteriores, en vez de usar palabras como pareja («compañero o compañera del sexo opuesto») o joven («que está en la juventud»), se utiliza la palabra mujer («persona del sexo femenino»), que es definitivamente más apropiada que pareja o joven, que son palabras que se usan para referirse tanto a hombres como a mujeres y que en este contexto son imprecisas.

5: Sobretitular: Indignación por fallo a favor de abusivo 
Titular: Jueza libera a pegalón

Subtitular: Fiscal pedía 9 meses de prisión preventiva para Luis Piscoya, quien fue gravado golpeando a chica desnuda en puerta de hostal en Piura

Cinco fotografías en la portada: de Luis Piscoya (agresor), de Misui Chávez (víctima), de Ubaldina Rojas (jueza) y dos imágenes de los videos.

Ojo, 19 de agosto de 2015, p. 1

\section{Comentario}

Nótese que en la noticia de la portada del diario, si bien se toma parte por la víctima y se destaca lo considerado por las autoridades (jueza y fiscal) y, además, se agregan fotos e imágenes, las palabras abusivo, pegalón y chica restan gravedad al hecho de violencia.

Véase cómo se define la palabra abusivo en el Diccionario de la lengua española (DLE 2014):

abusivo, va. [...] adj. [...] || 2. Que abusa, abusón. U. t. c. s.

abusar. (De abuso). intr. Usar mal, excesiva, injusta, impropia o indebidamente de algo o de alguien. Abusaba DE su autoridad. || 2. Hacer objeto de trato deshonesto a una persona de menor experiencia, fuerza o poder. Abusó DE un menor. [...]

Nótese que, de acuerdo con la segunda definición de abusivo, este es el «que abusa». En cuanto a abusar, su primera definición dice «Usar mal, excesiva, injusta, impropia o indebidamente»; mientras que la segunda acepción dice «Hacer objeto de trato deshonesto» (los resaltados son míos.) Por ello, el uso de la palabra abusivo es inapropiado por lo menos por dos razones: a) Misui Chávez no fue usada «mal, excesiva, injusta, impropia o indebidamente» (¡Misui Chávez no es un objeto!); Misui Chávez fue víctima de un maltrato bestial; b) Misui Chávez no fue «objeto de trato deshonesto»; Misui Chávez fue víctima de una brutal agresión física. Dicho de otro modo, el uso de la palabra abusivo no solo cosifica a la víctima sino también exculpa al agresor.

Véase, asimismo, cómo se define la palabra pegalón en el Diccionario de la lengua española (DLE 2014):

pegalón, na. adj. Méx. pegón (|| aficionado a pegar a otros). U. t. c. s.

pegón, na. adj. coloq. Aficionado a pegar golpes a otros. U. t. c. s. [...]

La palabra pegalón - que también se utiliza en el Perú- caricaturiza el hecho de violencia. ¿Cómo se explica que alguien sea «aficionado a pegar golpes a otros». Dicho de otro modo, ¿cómo alguien puede ser 
«aficionado» a golpear a una mujer o a cualquier otra persona? (En el DLE 2014, aficionado se define como el «que tiene afición o gusto por alguna actividad», "que cultiva o practica, sin ser profesional, un arte, oficio, ciencia, deporte, etc.». Y afición se define como «inclinación o atracción que se siente hacia un objeto o una actividad que gustan», "cariño, afecto o simpatía hacia alguien», "actividad que se realiza habitualmente y por gusto en ratos de ocio»). Nótese, pues, que la elección de las palabras, la selección léxica, requiere rigurosidad en cuanto a precisión se refiere.

Véase también cómo se define la palabra chica en el Diccionario de la lengua española (DEL, 2014):

chico, ca. [...] || 4. m. y f. Hombre o mujer, sin especificar la edad, cuando esta no es muy avanzada. [...]

En el contexto de la noticia, el uso de la palabra chica genera vaguedad. Dicho de otro modo, la palabra chica reemplaza a Misui Chávez y, por tanto, invisibiliza el nombre de la víctima.

\section{CASO 2}

Agresor: Adriano Manuel Pozo Arias (25)

Víctima: Cindy Arlette Contreras Bautista (26)

1. Sobretitular: Adriano Pozo Arias se entregó y fue internado en penal de Ayacucho

Titular: Abusivo ya está preso

Leyenda de fotografía: Procesado evitó dar declaraciones cuando era trasladado al penal para cumplir prisión preventiva

El Popular, 7 de agosto de 2015, p. 2

\section{Comentario}

Nótese, de acuerdo con el sobretitular, que no se sabe qué fue lo que hizo Adriano Pozo Arias: simplemente se dice que «se entregó y fue internado en penal de Ayacucho». Asimismo, en el titular se agrega: «Abusivo ya está preso» (no es ni agresor ni maltratador ni victimario) y, de acuerdo con la leyenda de la fotografía, Adriano Pozo Arias es el procesado («que ha sido objeto de procesamiento»), con lo que la vaguedad de la información se hace mayor.

En el desarrollo de la noticia se mantiene una postura parcializada a favor de Adriano Pozo Arias, a quien se victimiza. Se dice, por ejemplo: «No pudo más y se entregó», «padece de un trastorno límite de personalidad llamado también borderline». Así, ¿qué fue lo que hizo Adriano Pozo Arias?

2. Titular: Se entrega atacante de hotel en Ayacucho 
Subtitular: Adriano Pozo estuvo en la clandestinidad. Juzgado había ordenado prisión preventiva por 9 meses

Karibeña, 7 de agosto de 2015, p. 8

\section{Comentario}

Aunque en los dos primeros párrafos del desarrollo de la noticia se explicita que Adriano Pozo «agredió salvajemente», "golpeó desnudo a su pareja», después se le llama «joven» o se alude a él como «el hijo del regidor de Ayacucho»; además, se da voz a su abogada. Y la víctima, ¿por qué no tiene voz? (los subrayados son míos).

Hasta la sede del Poder Judicial de Ayacucho llegó la mañana de ayer Adriano Pozo Arias, el joven que la madrugada del 12 de julio agredió salvajemente $-\mathrm{y}$ completamente desnudo- a su entonces enamorada Cindy Contreras Bautista en un hotel de Huamanga, en la región Ayacucho.

Tras varias semanas en la clandestinidad, Adriano Pozo Arias, joven que golpeó desnudo a su pareja en un hotel, se entregó a la justicia de Huamanga. [...]

[...] el Primer Juzgado de Investigación Preparatoria dictó nueve meses de prisión preventiva contra el hijo del regidor de Ayacucho, Jorge Pozo.

[...] el Segundo Juzgado de Investigación Penal Preparatorio de Turno de la Corte Superior de Justicia de Ayacucho ordenó la prisión preventiva por nueve meses contra el joven, a quien se investiga por tentativa de feminicidio.

Rocío Laines, abogada de Adriano Pozo, insistió en lo que ya había indicado el padre del joven: que este padece de un trastorno límite de personalidad, conocido también como borderline. «Él, desde hace mucho tiempo, estaba siendo sometido a un tratamiento psicológico y psiquiátrico, con medicación», comentó.

Nótese que la palabra joven se utiliza hasta cuatro veces en el cuerpo de la noticia, con lo que se minimiza la agresión salvaje. La palabra joven se define como la persona «que está en la juventud», y juventud se define como el «periodo de la vida humana que precede a la madurez» (los resaltados son míos).

Por otra parte, el uso de la frase «hijo del regidor de Ayacucho» invisibiliza el nombre de Adriano Pozo Arias y, más bien, destaca el hecho de que es el hijo de una autoridad: del regidor de Ayacucho.

En cuanto a las declaraciones de la abogada de Adriano Pozo Arias, se presenta tanto una cita indirecta como una cita directa. Nótese que realmente las citas tienen doble aval, ya que se dice que la abogada «insistió en lo que ya había indicado el padre del joven». 
Y por si la parcialización a favor de Adriano Pozo Arias no fuese suficiente, se persiste en dar voz a su abogada, quien «consideró» $\mathrm{y}$ «sostuvo» (los resaltados son míos).

El dato

Asimismo, Laynes consideró que el caso podría tener detrás “una mano negra" y uuna cortina de humo». Además, sostuvo que la joven denunciante tendría contradicciones en su testimonio.

Obsérvense aquí dos frases que se usan en el Perú y que están muy bien definidas en el Diccionario integral del español de Argentina (2008): a) mano negra: «Persona cuya identidad no se conoce o no se quiere dar a conocer, que interviene ilícitamente en una situación para perjudicar a alguien» (p. 1118) y b) cortina de humo: «Acción o circunstancia usada para ocultar la realidad y desviar la atención» (p. 465). Nótese, pues, que al darle voz a la abogada, esta victimiza a Adriano Pozo Arias al atribuir a terceros la situación por la que este atraviesa y, además, pone en duda el testimonio de «la joven denunciante» (se obvia el nombre de la víctima de la agresión con lo que es invisibilizada).

\section{CASO 3}

Agresor: Edwin Joel Rodríguez Pérez (42)

Víctima: Matilde Silvia Moreno Barbudo (39)

1. Titular: La envenena por no regresar con él

Porque se negó a reiniciar su relación, el camionero Edwin Joel Rodríguez Pérez (42) asesinó a su exconviviente [...]

Trome, 6 de agosto de 2015, p. 4

\section{Comentario}

La noticia podría interpretarse como una amenaza velada: se insiste en señalar el porqué del asesinato, como si un crimen pudiera tener justificación alguna (los subrayados son míos).

2. Titular: Envenena a expareja y se cuelga para matarse

Leyendas de fotografía: Hombre habría actuado por celos / La víctima trabajaba de cocinera en el cementerio Campo Fe de Puente Piedra

Extra, 6 de agosto de 2015, p. 3

Enceguecido por los celos un iracundo sujeto dio muerte a su exconviviente [...]

\section{[...] culpaba a su expareja de provocar esa situación [...]}

Sobre las causas que llevaron a Rodríguez Moreno [sic] a atentar contra la vida de la mujer, el hermano de esta, William Moreno, 
señaló que los celos enfermizos de su cuñado, acompañado de la sospecha de un engaño, lo hicieron planificar el hecho. [...]

\section{Comentario}

Aquí también se insiste en señalar el porqué del asesinato, lo que implícitamente justifica el crimen: «enceguecido por los celos», «culpaba a su expareja», «las causas que llevaron a Rodríguez Moreno [sic] a atentar contra la vida de la mujer», "los celos enfermizos», «la sospecha de un engaño lo hicieron planificar el hecho». Se justifica el crimen presentando posibles causas. Nótese que incluso la cita indirecta acerca de lo que dice el hermano de la víctima también favorece al agresor (los subrayados son míos).

Obsérvese, asimismo, la frase «atentar contra la vida de la mujer»: decir «la mujer» es hacer uso de una expresión vaga y eufemística, pues Matilde Silvia Moreno Barbudo fue la conviviente de Edwin Joel Rodríguez Pérez y este la envenenó. Así pues, decir «la mujer» no solo implica invisibilizar un nombre sino también invisibilizar el tipo de parentesco entre la víctima y su victimario.

3. Sobretitular: Dejó cartas acusándola de infidelidad

Titular: Envenena a expareja y luego intenta ahorcarse

Leyenda de fotografía: Sujeto es custodiado las 24 horas por agentes de la Divincri en hospital

El Popular, 6 de agosto de 2015, p. 5

\section{Comentario}

Nótese cómo se victimiza al agresor: este «Envenena a su expareja y luego intenta ahorcarse», «Dejó cartas acusándola de infidelidad».

Asimismo, en el desarrollo de la noticia se insiste en la parcialización a favor de Edwin Joel Rodríguez Pérez. Obsérvese especialmente el orden de los componentes oracionales: «Abrumado por la duda de los celos»: primero la causa justificante, para finalizar con «luego intentó quitarse la vida», que funciona como una manifestación de arrepentimiento (los resaltados son míos).

Abrumado por la duda de los celos, un obrero envenenó con raticida a la madre de su hijo y luego intentó quitarse la vida ingiriendo la misma bebida [...]

En el siguiente párrafo se justifica el envenenamiento de Matilde Silvia Moreno Barbudo, que «había iniciado una relación con otra persona» (los subrayados son míos).

[...] dio de beber gaseosa mezclada con raticida a su expareja Matilde Silvia Moreno Barbudo (39), luego de descubrir que había iniciado una relación con otra persona. 
Y por si no bastase hasta aquí con la parcialización a favor del agresor Edwin Joel Rodríguez Pérez, se presenta una cita directa para seguir victimizándolo. Con esta redacción tendenciosa se busca generar lastima por el agresor y culpabilizar a la víctima.

«Ella siempre me engañaba, me humillaba, se burlaba de mí, por favor, cuiden a mi Darío», decía una de las cartas halladas en la habitación por la policía.

Solo en un párrafo y a través del uso de la cita indirecta se da voz a los familiares de Matilde Silvia Moreno Barbudo.

Según los familiares de la víctima, Rodríguez Pérez habría tenido planificado el crimen, pues se aseguró de quedarse sin testigos para envenenarla.

4. Titular: Mujer muere envenenada por su expareja

Exitosa, 6 de agosto de 2015, p. 11

Obligada a tomar un potente raticida. Así halló la muerte Matilde Silvia Moreno Barbudo, comerciante de 39 años, victimada por su expareja, el transportista Edwin Joel Rodríguez Pérez. Tras golpearla, el hombre le dio de beber veneno en venganza por una supuesta infidelidad. [...] «Él la celaba y golpeaba. Ya antes la había amenazado de muerte», contaron. El asesino habría planificado a detalle su crimen, pues en horas previas se ocupó incluso de sacar a su hijo de ocho años de la casa, para quedar a solas con la fémina. [...] Intentando justificar su actuar, el hombre dejó una nota en que culpaba de infidelidad a la mujer.

\section{Comentario}

En este diario, a diferencia de los anteriores, se toma parte por la víctima Matilde Silvia Moreno Barbudo e incluso se explicita una cita directa («Él la celaba y golpeaba. Ya antes la había amenazado de muerte») en la que se expone la conducta del agresor, que es presentado de tres maneras: con su nombre completo (Edwin Joel Rodríguez Pérez), como «el hombre» y como «el asesino».

\section{CASO 4}

Agresor: Jean Carlos Francisco Deza Sánchez (22)

Víctima: Kleydy Gissel Rossi Medina

1. Sobretitular: Capturan a jugador Jean Deza por agredir a su esposa Titular: Aliancista preso por pegalón

Subtitular: Cuando se disponía a viajar a Francia, fue detenido en el aeropuerto por estar requisitoriado. Tiene cuatro denuncias de su esposa por agresión e intento de homicidio. 
Tres fotografías en la portada: de Jean Deza con la camiseta del club Alianza Lima, de la víctima con el rostro golpeado (Kleydy Rossi Medina, esposa), de Jean Deza y Kleydy Rossi Medina abrazados.

Ojo, 7 de agosto de 2015, p. 1

\section{Comentario}

Es difícil encontrar en la portada de un diario una noticia acerca de la agresión física ejercida por un jugador de fútbol.

1.1. Sobretitular: Futbolista tiene cinco denuncias por agresión y «lo bajaron» del avión cuando pensaba viajar a Francia

Titular: Deza, preso por pegalón

Leyenda de fotografía: Su esposa lo denunció de agredirla hasta en cuatro ocasiones y por intento de homicidio

Ojo, 7 de agosto de 2015, pp. 12-13

\section{Comentario}

En el desarrollo de la noticia se reproduce textualmente (incluso en cursivas y con negrita) las declaraciones de la víctima Kleydy Gissel Rossi Medina, a quien se da voz ampliamente (los subrayados son míos, no las negritas ni las cursivas).

Abusivo y pegalón. El futbolista nacional Jean Carlos Francisco Deza Sánchez (22) pasó la madrugada de ayer tras las rejas, luego de ser detenido justo cuando subía al avión que lo llevaría a Francia para integrarse al club Montpellier HSC, tras ser acusado por su esposa de agresión e intento de homicidio.

El polémico pelotero durmió en un calabozo de la sede de Requisitorias de la Policía Nacional, en la avenida Canadá, después de ser intervenido en Migraciones del aeropuerto Jorge Chávez.

Deza Sánchez, desvinculado recientemente de Alianza Lima, tiene hasta cinco denuncias por maltrato físico, informó su esposa Kleydy Gissel Rossi Medina.

"Lo van a pasar al Juzgado de San Miguel y será el juez quien determinará si va preso o no», señaló Kleydy.

«Él tiene cinco denuncias por agresión física. Yo le puse cuatro. La primera es del año 2011 y las restantes son de este año», precisó.

Ella aseguró que cuando fue a pedirle dinero para los gastos de la hija de ambos, el futbolista «la ahorcó, le tiró una patada y la empujó al suelo».

"Toda su familia sabe que estoy esperando un nuevo hijo de Jean, pero el hermano me "metió" el carro con intenciones de atropellarme. Realmente es lamentable todo esto y temo por mi vida, ya que desde la cárcel me viene amenazando", dijo Kleydy Rossi [...]. 
«Detrás de todo esto también está su otro hermano que está en prisión», denunció Rossi. Precisó que espera que se haga justicia y el futbolista sea condenado por todas las agresiones en su contra.

También se da voz a la policía (la autoridad), aunque al ver las fotografías de Kleydy Rossi Medina cabe preguntarse qué es lo que se va a comprobar si en estas son evidentes las secuelas de la agresión.

\section{Algo más}

La Policía pidió al director del Instituto de Medicina Legal de Lima un examen de reconocimiento médico a Kleydy Rossi para comprobar si presenta lesiones.

Pero, al parecer, de nada vale la denuncia, ya que, de acuerdo con la noticia, Ronald Baroni, representante de Jean Carlos Francisco Deza Sánchez, dice:

«Mis abogados solucionarán de la mejor manera esto. Jean va a viajar pronto a Montpellier».

Ronald Baroni, representante de Deza

2. Titular: Deza está detenido

Subtitular: Se truncó su viaje a Francia para incorporarse al MontpeIlier, club al que aún pertenece

Diario Uno, 7 de agosto de 2015, p. 22

\section{Comentario}

De acuerdo con el titular y el subtitular, "Deza está detenido» y «Se truncó su viaje» sin causa alguna.

Es en el desarrollo de la noticia donde se explicitan las causas de la detención de Jean Deza, fundamentalmente a través de citas directas de las declaraciones de Kleydy Rossi, su esposa, no «su pareja sentimental», frase imprecisa con la que se evita explicitar el parentesco entre el victimario y la víctima (los resaltados son míos.)

Deza [...] tiene varias denuncias emitidas por su pareja sentimental, Kleydy Rossi, quien lo acusa de maltrato físico. La agraviada confirmó la lamentable situación del atacante nacional. «Jean tiene cinco denuncias por agresión física, yo le puse cuatro de ellas, siendo la primera en el 2011 y las restantes en este 2015. Además, una chica de apellido Pereyra también le puso una demanda por agresión física, ya que le rompió el tabique. Lo peor de todo fue que Jean no se presentó a ninguna citación y ahora está envuelto en este problema». [...]

Posteriormente se presenta un párrafo en el que se observa un matiz de conmiseración respecto del agresor (los resaltados son míos). 
Este suceso podría bien marcar la caída de su [...] carrera deportiva del delantero que incluso reforzó a la selección nacional que realizó una gira por Europa. [...]

\section{CASO 5}

Agresor: Wilson Gómez Tito (29)

Víctima: Emily Karen Neyra Beltrán (27)

1. Sobretitular: No le importó que sus tres hijitos le pidan piedad Titular: Degolló a su pareja

Subtitulares: Mujer quiso terminar relación cansada de los maltratos / La acuchilló más de diez veces en su casa y luego escapó del lugar / En Facebook escribió mensaje que adelantaba su macabro plan. Policía lo capturó.

El Popular, 19 de agosto de 2015, p. 1

\section{Comentario}

En esta noticia de la portada del diario se sumillan los hechos sin tomar parte por el agresor, aunque tampoco se explicita su nombre ni el de su víctima.

\subsection{Titular: Albañil mata a conviviente}

Leyendas en fotografía: La acuchilló más de diez veces y la degolló delante de tres hijos que pedían piedad / Cuerpo de Emily, quien vivía con su asesino y sus tres niños, fue trasladado a la Morgue Central

El Popular, 19 de agosto de 2015, p. 2

\section{Comentario}

En el desarrollo de la noticia, se justifica a Wilson Gómez Tito al destacar como causales del crimen los celos y el odio, fue «un arranque de locura», «no soportó que Emily Karen Neyra Beltrán [...] diera por terminada la relación de 12 años de convivencia» (los resaltados son míos).

Celos y odio. En un arranque de locura y sin importarle la presencia de sus tres pequeños hijos de 6,8 y 10 años, un albañil asesinó a cuchilladas a su conviviente tras una pelea en su vivienda de Chorrillos.

Wilson Gómez Tito (29) no soportó que Emily Karen Neyra Beltrán (27), cansada de los golpes e insultos, diera por terminada la relación de 12 años de convivencia.

También en el segundo párrafo del desarrollo de la noticia se justifica el ataque cuando se dice que «el hombre le reclamó tener otra pareja», «Gómez perdió los papeles». A partir de esto, el crimen se relata a modo de una receta de cocina (los resaltados son míos). 


\section{Celos y ataque}

Se supo que todo se inició con una discusión en la que el hombre le reclamó tener otra pareja. Ella lo negó y le dijo que todo se acabó.

Gómez perdió los papeles y le infirió al menos diez cortes en el abdomen y pecho. Finalmente, la degolló. [...]

En el párrafo de cierre, se justifica la agresión de Wilson Gómez Tito, a quien se califica como el «enajenado padre de familia». Y aunque se dice que es un «feminicida», se agrega, fuera de contexto, que este «últimamente se encontraba desempleado».

\section{Niños pedían piedad}

Los pequeños hijos de la pareja entraron en shock e imploraban piedad al padre.

«¡Cállense, mi...!», escuchó un vecino gritar al enajenado padre de familia.

Tras cometer su delito, el feminicida, que últimamente se encontraba desempleado, escapó del lugar. [...]

1.2. Sobretitular: «Siempre te llevaré en mi corazón», escribió a víctima en Facebook

Titular: Habría tenido todo planeado

Leyenda de fotografía: Sujeto fue puesto a disposición de la fiscalía

El Popular, 19 de agosto de 2015, p. 2

\section{Comentario}

Nótese que aunque en el titular se dice: «Habría tenido todo planeado», en el desarrollo de la noticia se victimiza y se justifica el accionar de «el detenido Wilson Gómez Tito (29), quien en todo momento tenía la mirada perdida y escondía su rostro» y que "confesó que había actuado mortificado porque la madre de sus hijos le habría sido infiel». Este es otro tipo de causal al que muchos agresores recurren para su defensa: las mujeres mancillan el «honor» del hombre, como si el honor se correspondiese solo con la fidelidad de las mujeres; mientras que la infidelidad de los hombres no es condenable, sino, más bien, elogiable (los resaltados son míos).

Durante su traslado a los exámenes médicos, el detenido Wilson Gómez Tito (29), quien en todo momento tenía la mirada perdida y escondía su rostro, evitó hablar con la prensa. [...]

Sin embargo, ante la Policía en un primer momento confesó que había actuado mortificado porque la madre de sus hijos le habría sido infiel.

En el siguiente bloque del desarrollo de la noticia se destaca que el crimen habría sido planeado, lo cual se sustenta a través de la cita del 
mensaje que Wilson Gómez Tito escribió en Facebook, mensaje en el que «adelantaría sus intenciones» (los resaltados son míos).

\section{Lo habría planeado}

Dos días antes en su Facebook le escribió un mensaje a su víctima, donde adelantaría sus intenciones.

«Te quiero, Emily. Contigo compartí muchas cosas lindas y malas pero aun así pudimos seguir adelante. Gracias por darme tres hijos maravillosos, eres una mamá ejemplar. A tu edad eres una mujer madura, te admiro mucho». Y solo 19 horas antes de cometer su delito escribió: «Siempre te llevaré en mi corazón» [...]

Existe una publicación titulada No te mueras por mí (2015) en la que se puede hallar una importante casuística de textos epistolares en los que se observa que, a fin de ser perdonados por sus víctimas, los agresores se muestran arrepentidos, aseguran que van a cambiar y afirman que aman a su enamorada, conviviente o esposa antes de volver a agredirlas o antes de consumar el feminicidio.

2. Sobretitular: En Chorrillos

Titular: La mata a puñaladas delante de sus hijos

Diario Uno, 19 de agosto de 2015, p. 17

\section{Comentario}

En esta noticia, a diferencia de la anterior que trata acerca del mismo caso, se visibiliza el feminicidio. Además, se explicita que «hace 3 años, el agresor ya había atentado contra la vida de Emily Neyra atacándola con un martillo» y que el «ataque consta en una denuncia en la comisaría»; es decir, que las autoridades no intervinieron a tiempo para evitar el feminicidio (los resaltados son míos).

Una joven madre de familia fue asesinada de 15 puñaladas delante de sus tres menores hijos por su esposo [...], en un nuevo caso de feminicidio en el país.

A las 6 de la mañana de ayer, los vecinos y familiares [...] se despertaron con los gritos de Emily Neyra Beltrán (27), que ya estaba agonizando luego de haber sido apuñalada por Wilson Gómez Tito (29).

Los motivos del crimen — según familiares y vecinos - fueron debido a que la mujer había decidido terminar la relación que llevaba más de 12 años [...].

Según la tía de la víctima, las peleas y discusiones eran frecuentes en la pareja, por lo que habían decidido finalizar la relación. Además, hace 3 años, el agresor ya había atentado contra la vida de Emily Neyra atacándola con un martillo. Este ataque consta en una denuncia en la comisaría del distrito. [...] 
Como se podrá observar en la compilación testimonial No te mueras por mí (2015), los agresores no corrigen su conducta: sus palabras solo tienen como fin generar en la víctima una sensación de confianza para, conseguido su objetivo, retomar el control a fin de volver a agredirla o a fin de asesinarla (los resaltados son míos.)

\section{Mensaje por Facebook}

Sin embargo, el último domingo en la red social Facebook, el asesino le envió un mensaje a su conviviente donde aparentemente aceptaba la ruptura de la relación, pero luego de la tragedia, parece que más bien fue una maniobra para encontrar con la guardia baja a su esposa.

\section{CASO 6}

Agresor: Héctor Manuel Cabrera Flores (27)

Víctima: Gloria Stephani Ruiz Jesús (22)

1. Titular: Denuncia que esposo PNP la molió a golpes

Extra, 19 de agosto de 2015, p. 2

\section{Comentario}

En esta noticia, que trata acerca de la agresión perpetrada por el suboficial Héctor Manuel Cabrera Flores, se da voz a la víctima Gloria Stephani Ruiz Jesús, quien «denunció» y «sostuvo» (los resaltados son míos).

Una joven madre de familia, identificada como Gloria Stephani Ruiz Jesús (22), denunció a su esposo, el suboficial de tercera Héctor Manuel Cabrera Flores (27), de haberla golpeado en reiteradas ocasiones por reclamarle sus presuntas infidelidades. La agraviada sostuvo que el efectivo, con quien tiene dos años de relación y una hija de la misma edad, trabaja en la comisaria de Villa María del Triunfo y hace servicio en uno de los llamados patrulleros inteligentes.

Además, se cita textualmente a la víctima Gloria Stephani Ruiz Jesús cuando denuncia a su agresor, el suboficial Héctor Manuel Cabrera Flores, porque ya no soporta más la situación (los resaltados son míos).

«Es la primera vez que lo denuncio porque ya no soporto esta situación. Ayer lunes fue la última vez que me agredió delante de mi hija por reclamarle las fotos que encontré en su celular, donde se le ve con otra mujer intimando», indicó.

Incluso en el desarrollo de la noticia se hace explícito a la opinión pública que la víctima está «solicitando garantías para su vida», por lo que las autoridades pertinentes serían responsables si Gloria Stephani Ruiz Jesús fuese asesinada por Héctor Manuel Cabrera Flores. 
La joven mujer sostuvo que también ha sido amenazada de muerte por su pareja, por ello viene solicitando garantías para su vida.

Se debe señalar que en el Perú, en el caso de personal de las Fuerzas Policiales o de las Fuerzas Armadas, es más probable que el agresor evite reincidir en la agresión física, no necesariamente porque se reforme, sino por temor a ser despedido de su centro laboral.

2. Sobretitular: Llegó con el ojo hinchado a comisaría

Titular: Suboficial PNP agrede a puñetazos a su pareja

Leyenda de fotografía: Recalcó que siempre la agrede

El Popular, 19 de agosto de 2015, p. 5

\section{Comentario}

En este diario también se da voz a la víctima de la agresión, Gloria Stephani Ruiz Jesús. Se explicita la lesión («el ojo hinchado», «una evidente hinchazón en el ojo izquierdo»), se indica quién la agredió (el «suboficial PNP Héctor Manuel Cabrera Flores») y de qué manera («a puñetazos», «golpizas»); asimismo, se señala la recurrencia de la agresión (siempre la agrede).

En el desarrollo de la noticia se detallan los datos acerca de la agresión física perpetrada por el suboficial PNP Héctor Manuel Cabrera Flores y se da voz a la víctima Gloria Stephani Ruiz Jesús a través de la cita directa e indirecta (los resaltados son míos).

El suboficial PNP Héctor Manuel Cabrera Flores (27) fue denunciado por su conviviente, Gloria Stephani Ruiz Jesús (22), por agresión física en la comisaría de San Genaro, en Chorrillos.

La joven con su hijo en brazos y una evidente hinchazón en el ojo izquierdo, producto de las golpizas, acudió en la mañana de ayer a la sede policial.

«Es por infidelidad. Yo le encontré un USB en una situación íntima con una mujer. Cuando le reclamé me atacó sin piedad», reveló.

Según contó la joven madre, la agresión ocurrió la tarde del domingo en su vivienda que comparten hace dos años en la Asociación Enatru en San Genaro Chorrillos, de propiedad de sus suegros.

En el segundo bloque de la noticia se da voz a la víctima para señalar que el policía la agrede desde «marzo pasado» y «siempre que discuten es atacada a puñetazos». Asimismo, se explicita que la víctima «presenta numerosas lesiones en el rostro, cuello y brazos» y que «el policía la ha amenazado de muerte y su vida corre peligro» (los resaltados son míos.) 


\section{Primera vez}

La mujer dijo que es la primera vez que lo denuncia, luego de descubrir su infidelidad en marzo pasado.

Desde ese tiempo y siempre que discuten es atacada a puñetazos por el policía.

Los agentes de la comisaría de San Genaro investigan el caso y han ordenado que la joven pase por el médico legista. Ella presenta numerosas lesiones en el rostro, cuello y brazos.

Luego citarán al agente policial que presta servicios en un patrullero inteligente en Villa María del Triunfo, para ser interrogado sobre la denuncia en su contra.

«Me ha atacado a puñetes en diversas partes del cuerpo. Siempre que le reclamo me agrede. Esta vez, aprovechando que está en su trabajo, he venido a realizar la denuncia», dijo la agraviada. La denunciante dijo que el policía la ha amenazado de muerte y su vida corre peligro.

Nótese que la declaración de la víctima se corresponde con lo que se parafrasea antes.

\section{CASO 7}

Agresor: Vladimir Meza Villarreal

Víctima: Mirian Hidalgo Romero

1. Sobretitular: Vladimir Meza, exalcalde de Huaraz, dirige la campaña en la región Áncash

Titular: Jefe de campaña de PPK investigado por brutal golpiza a su mujer

Exitosa, 19 de agosto de 2015, p. 9

\section{Comentario}

En la noticia, la selección léxica apunta al desempeño político del agresor Vladimir Meza. Y aunque en el sobretitular se explicita su nombre, inmediatamente después pasa a ser el «exalcalde de Huaraz», «jefe de campaña de PPK».

En el primer párrafo del desarrollo de la noticia se parafrasea el dictamen de la fiscalía, respecto del que se dice que «pone en jaque a Vladimir Meza Villareal», quien «tiene mucho que responder tras ser denunciado por violencia familiar»y, además, se involucra a Pedro Pablo Kuczynski (PPK), con lo que se politiza la noticia y se deja al margen el tema central, que es la agresión a Mirian Hidalgo Romero y a la niña que es hija de ella y de Vladimir Meza Villareal. 
Además, nótese en el desarrollo de la noticia que se trata de un hecho de violencia suscitado «el 19 de diciembre de 2014», por lo que llama la atención el repentino interés por el caso ocho meses después de ocurrido, sobre todo porque en el Perú nos encontramos este año (2015) en medio de la campaña política con miras a las próximas elecciones presidenciales de 2016, y Pedro Pablo Kuczynski es uno de los candidatos (los resaltados son míos).

El dictamen 06-2015 de la Primera Fiscalía Provincial de Familia de Huaraz, a cargo de la fiscal Dayli Jennifer Montalvo Coraje, pone en jaque a Vladimir Meza Villareal, pues confirma que el actual jefe de campaña de PPK en dicha ciudad tiene mucho que responder tras ser denunciado por violencia familiar, en la modalidad de maltrato físico y psicológico, en agravio de su conviviente Mirian Hidalgo Romero y la menor V.C.M.H. ¿Sabía de estos antecedentes Pedro Pablo Kuczynski?

En el siguiente párrafo se da voz a una representante del Ministerio Público, quien explica cómo se inició la agresión (cuando «la agraviada [...] cogió una maleta a fin de llevar todas sus pertenencias y abandonar el lugar») y cuál fue el accionar de Vladimir Meza («el exalcalde huaracino la coge de los cabellos y la tumba al piso», "el demandado no se inmutó y continuó agrediéndola con patadas y puñetes en todo el cuerpo»). Obsérvese también que en este párrafo Vladimir Meza es llamado el «exburgomaestre», el «exalcalde huaracino» o «el demandado» (los subrayados son míos).

\section{Alcohol y violencia}

De acuerdo [con] la representante del Ministerio Público, el 19 de diciembre de 2014, aproximadamente a las 22:00 horas, cuando la agraviada se encontraba en su domicilio acompañada de la menor V.C.M.H., Vladimir Meza llegó en aparente estado de ebriedad y le pidió a su cónyuge que ella asista por él a una inauguración pública, a la que fue invitado Meza. [...]

Al obtener una respuesta negativa, el exburgomaestre le replicó a la agraviada y le dijo que «se encontraba tomado y que no podía ir». Según la denuncia, Meza le volvió a levantar la voz a su pareja y señaló que «no le sabe entender, ya que él tenía problemas», produciéndose reclamos con insultos.

"iYa basta! Si quieres, me voy del departamento para que busques otra mujer de tu nivel», le respondió la agraviada, quien casi al mismo tiempo cogió una maleta a fin de llevar todas sus pertenencias y abandonar el lugar. Es aquí cuando el exalcalde huaracino la coge de los cabellos y la tumba al piso. 
«Suéltala, suéltala», fueron las palabras de desesperación que emitió la menor. Pese a ello, el demandado no se inmutó y continuó agrediéndola con patadas y puñetes en todo el cuerpo.

En otro párrafo se explicitan, con pormenorizado detalle, las lesiones sufridas por «la agraviada» de acuerdo con la autoridad fiscal (los resaltados son míos).

\section{Las lesiones}

La fiscal Montalvo Coraje refiere que la agraviada es conviviente del denunciado Vladimir Meza y que los maltratos físicos causados se encuentran acreditados con el certificado médico legal.

Entre ellos destacan distintos tipos de equimosis, es decir, lesiones subcutáneas caracterizadas por depósitos de sangre extravasada debajo de la piel intacta: color violáceo en región párpado superior izquierdo, color rojo en región frontal derecha, color verde en región lateral de hemitórax izquierdo y color rojo en región posterior tercio distal antebrazo izquierdo. Además, de una hinchazón en la región interparietal.

Por estas y otras numerosas lesiones, se le otorgó a Mirian Hidalgo tres días de atención facultativa y ocho días de incapacidad médico legal.

Asimismo, se explicita el daño psicológico sufrido por «la afectada» y por «la menor» (su hija) (el resaltado es mío).

\section{Niña afectada}

Tanto la afectada como la menor presentaron «reacción mixta depresiva-ansiosa moderada y evidencian indicadores emocionales de maltrato psicológico asociado al hecho de la denuncia».

A continuación, se da voz a Vladimir Meza a través de una entrevista con diario Exitosa. Obsérvese en el primer párrafo el uso del conector de contraste pero, que destaca la proposición que le sigue (segunda proposición): «reconoció la denuncia de violencia familiar, pero calificó los hechos como "malentendidos"». Nótese que la palabra malentendidos también forma parte de la sumilla de la noticia (los resaltados son míos).

\section{Califica hechos denunciados como «malentendidos»}

En diálogo con diario Exitosa, Vladimir Meza, a su estilo, reconoció la denuncia de violencia familiar, pero calificó los hechos como «malentendidos».

En el siguiente párrafo se dice, respecto también de Vladimir Meza, que «él se había disculpado con la agraviada en su momento». ¡Como si las disculpas eliminaran las agresiones! Y luego se cita lo declarado por Vladimir Meza: «todo está bien, con las cosas de cualquier pareja normal». 
¿Y qué se deberá entender por «todo está bien» o «pareja normal»? Páginas antes se citó lo señalado por Ramos (2006, p. 129): los hombres que usan la violencia física contra la mujer afirman, en su mayoría, que sus relaciones de pareja son «buenas y armónicas» (los resaltados son míos).

Indicó que tanto él como su pareja solicitaron el archivamiento del caso porque él se había disculpado con la agraviada en su momento. «Lo importante es que todo está bien, con las cosas de cualquier pareja normal», indicó.

Y en el último párrafo se explicita la política del Estado peruano y el dictamen del fiscal (los resaltados son míos).

Sin embargo, ello no lo exime de su responsabilidad pues debe afrontar las consecuencias de su accionar violento, más cuando es política permanente del Estado luchar contra toda forma de violencia familiar. Es más, el propio fiscal es categórico en su dictamen y le advierte al juez que no se le puede absolver del delito por más que ambos se hayan reconciliado.

A diferencia de las noticias anteriores, en este caso se observa un doble discurso direccionado al tema político: se expone al detalle la agresión sufrida por Mirian Hidalgo Romero y los descargos de Vladimir Meza Villarreal; pero esto es solo un pretexto para destacar en qué consistió la agresión de la que se responsabiliza a Vladimir Meza Villarreal, jefe de campaña de Pedro Pablo Kuczynski. Con lo dicho no pretendo disculpar de ninguna manera el hecho de violencia; lo que digo es que, de acuerdo con la información, que se expone aquí ocho meses después de suscitados los hechos, más que la agresión en sí, lo que interesa es visibilizar el quehacer político de Vladimir Meza Villarreal y su relación con el candidato a la presidencia Pedro Pablo Kuczynski. El hecho de violencia es simplemente un recurso para el ataque político.

\section{CASO 8}

Agresor: Néstor Antonio Yauri Inga (35)

Víctima: Yovana Yaquel Román Macote (32)

1. Sobretitular: Hallan cuerpo descuartizado de mujer en maleta Titular: Basta de feminicidios / ¡HORROR!

Subtitulares: Familiares acusan a su pareja quien les confesó el crimen y luego fugó. / Madre de tres niños había desaparecido hace dos días de su casa. / Asesino dijo que dejó el cadáver cercenado cerca del Puente Carapongo en Ate.

El Popular, 20 de agosto de 2015, p. 1 


\section{Comentario}

Posiblemente se califique a la noticia de sensacionalista; sin embargo, todo acto de violencia debe visibilizarse, y los actos de violencia contra las mujeres son cada vez más recurrentes. Nótese las frases usadas para la presentación de la noticia: «Hallan cuerpo descuartizado de mujer», «Basta de feminicidios», «Asesino dijo que dejó el cadáver cercenado» (los resaltados son míos).

1.1. Sobretitular: Conviviente confesó por teléfono terrible crimen a los familiares

Titular: Hallan a una mujer descuartizada dentro de una maleta en Ate

Subtitular: Víctima era madre de tres niños y quería terminar relación por maltratos

El Popular, 20 de agosto de 2015, p. 3

\section{Comentario}

Obsérvese que se explicita tanto el nombre de la víctima, Yovana Yaquel Ramón Macote, como el del victimario, Néstor Antonio Yauri Inga. Él es calificado como «conviviente», «pareja», «feminicida», «homicida», «desalmado», «agresor», «asesino»; ella es denominada «víctima», «humilde vendedora», «madre de tres hijos», «infortunada», «mujer», «conviviente», «occisa». Respecto de lo sucedido, se dice «terrible crimen», «crimen sin nombre», «con total sangre fría», «dentro de una maleta negra de lona» (los resaltados son míos).

Crimen sin nombre. Descuartizada y dentro de una maleta fue encontrada anoche una humilde vendedora de piña a la altura del km 14 de la carretera Central, Ate.

Yovana Yaquel Ramón Macote (32), madre de tres hijos, había desaparecido hace dos días y sus familiares la buscaban desesperadamente.

\section{Admitió la verdad}

Sospechaban de la pareja de la infortunada, Néstor Antonio Yauri Inga (35), quien al inicio aseguraba que no sabía nada sobre su paradero. Sin embargo, no creyeron en su palabra.

Según los familiares, le insistieron hasta que, a las 8:00 p. m. de ayer, con el cargo de conciencia encima, Yauri Inga los Ilamó por teléfono y les confesó la verdad.

El feminicida, con total sangre fría, les detalló que había dejado el cadáver a 15 metros del puente Carapongo.

De inmediato acudieron al lugar con la policía y encontraron los restos de Yovana dentro de una maleta negra de lona. El shock fue 
terrible para los deudos, que lograron reconocerla por la ropa que llevaba puesta.

\section{Asesino prófugo}

En tanto, el paradero del homicida es un misterio. Amigos y familiares de Yovana describieron al desalmado como muy celoso y recordaron que la agredía físicamente. Debido al maltrato, ella deseaba separarse, pero esto no era aceptado por su agresor. Hasta el lugar llegaron peritos de la Divincri, que señalaron que la mujer habría sido asesinada el mismo día.

\section{Pruebas en vivienda}

Los detectives revisarán la vivienda de Néstor Yauri. Según las pesquisas, en ese lugar habría descuartizado a su conviviente. Ello para encontrar pruebas del crimen. Familiares de la occisa pidieron justicia y que capturen al asesino. Aseguraron que siempre sospecharon de su pareja, pues amenazaba con asesinarla si lo dejaba.

\section{Toma nota:}

Efectivos de la Divincri buscan las cámaras cercanas a la zona del crimen.

Nótese lo pormenorizado de la información respecto del crimen, así como la selección léxica que visibilizan con bastante claridad el hecho de feminicidio (los resaltados son míos).

\section{Titular: Atrapan a asesino de la maleta}

Subtitular: La mató a martillazos porque víctima se iba a ir a Estados Unidos. Criminal fue capturado en Pucallpa cuando pretendía huir a Brasil.

Diario Uno, 21 de agosto de 2015, p. 17

\section{Comentario}

Obsérvese que, en el titular, al victimario se le llama el «asesino de la maleta» y en el subtitular, a través del conector causal porque, se presenta la causa del crimen: «porque víctima se iba a ir a Estados Unidos». Es decir, se sustituye el nombre del criminal y, asimismo, se plantea una razón para la ejecución del crimen (los resaltados son míos).

Por otra parte, en el primer párrafo del desarrollo de la noticia, se explicita el nombre de Néstor Yauri Inga, quien «asesinó en su propio hogar a su esposa Yovana Raquel Román Macote». Asimismo, se insiste en justificar el asesinato y se victimiza al asesino: «golpeándola con un martillo en la cabeza porque esta [su esposa Yovana Raquel Román Macote] se iba a ir a vivir a Estados Unidos abandonándolo luego de una larga relación que había dado como fruto tres hijos» (los resaltados son míos). 
Néstor Yauri Inga (38) asesinó en su propio hogar a su esposa Yovana Raquel Román Macote (32) golpeándola con un martillo en la cabeza porque esta se iba a ir a vivir a Estados Unidos abandonándolo luego de una larga relación que había dado como fruto tres hijos.

Nótese en el siguiente párrafo que, habiéndose señalado que «el asesino demostró una increíble sangre fría ya que metió el cuerpo de su esposa dentro de una maleta», se dice inmediatamente después que «dejó el equipaje en las laderas del río»; es decir, «el cuerpo» de Yovana Raquel Román Macote pasa a ser «el equipaje» (los resaltados son míos).

Luego de perpetrado el crimen en su vivienda en Ate Vitarte —los peritos aseguran que el crimen se cometió el mismo día en que desapareció la infortunada mujer (el lunes 17 de agosto) - el asesino demostró una increíble sangre fría ya que metió el cuerpo de su esposa dentro de una maleta negra y dejó el equipaje en las laderas del río Rímac, a la altura del puente de Carapongo.

El criminal fue capturado ayer en Pucallpa cuando intentaba fugar hacia Brasil. Fue detenido en el cruce de los jirones Ucayali y 9 de Octubre por un policía, ya que fue reconocido por la foto publicada en la prensa.

Se debe señalar aquí un aspecto importante. Se trata de la visibilización de los agresores a través de las imágenes: «El criminal fue capturado [...] ya que fue reconocido por la foto publicada en la prensa». Y es que en el Perú se tiende a exponer el rostro de los agresores independientemente del sector laboral o del grupo social al cual pertenezcan; de esta manera se favorece su identificación, aunque no siempre su captura o el correspondiente proceso judicial.

Por otra parte, obsérvese que el accionar de las autoridades policiales y judiciales se explicita a través de citas indirectas y directas, y la confesión de Néstor Yauri Inga, a través de citas indirectas (los resaltados son míos).

Lo traen hoy

El jefe de la Dirandro de Pucallpa, el coronel Francisco Bartra Arévalo, detalló que Yauri fue detenido ayer a las 10:30 e informó que hoy estará de vuelta en la capital, donde continuarán las investigaciones a cargo de la Dirincri de Ate.

Mientras tanto, el Ministerio Público ha solicitado su detención a través de la Segunda Fiscalía Provincial Penal de Santa Anita.

Agregó que el propio Néstor Yauri Inga confesó el crimen y relató que llegó a Pucallpa el martes último con la intención de abordar una embarcación fluvial para escapar.

«Tomó un bus desde Lima y llegó a las 18 horas del martes a Pucallpa. Ha confesado el crimen. Acepta que es el autor y está a buen 
recaudo. Espero que las autoridades apliquen todo el peso de la ley», declaró el coronel.

En el siguiente segmento de la noticia se continúa visibilizando, a través de citas indirectas, el accionar de Néstor Yauri Inga. Asimismo, se explicitan las acciones Ilevadas a cabo por los peritos de criminalista (los resaltados son míos).

\section{Informó a la familia}

El pasado miércoles en la tarde, Yauri tuvo el desparpajo de llamar a los familiares de la víctima y decirles el lugar exacto donde se encontraba el cadáver de su esposa. Aseguró que pronto iba a tomar una decisión: entregarse a la justicia o suicidarse. Al parecer dio esta versión para ganar tiempo, porque ya se encontraba en Pucallpa.

Los peritos de criminalística ingresaron a la casa que fue escenario del crimen y las pruebas de luminol demostraron rastros de sangre. Un perito dijo que el asesino había intentado borrar las evidencias, sin éxito.

En el último párrafo de la noticia se trata acerca de la «pareja», que «tenía tres hijos menores»; la vivienda, ubicada «a pocos metros donde fue hallada la maleta»; lo que hacía la víctima: «La mujer vendía piñas en el mercado») y el victimario: «El asesino no trabajaba y solo se dedicaba al juego» (los resaltados son míos).

\section{Además}

La pareja tenía tres hijos menores, con quienes vivían en Asociación Provivienda Los Claveles de San Juan, Mz. A, Lt. 6, a pocos metros donde fue hallada la maleta. La mujer vendía piñas en el mercado Los Sauces. El asesino no trabajaba y solo se dedicaba al juego, según los vecinos.

En esta noticia se maneja un discurso ambivalente: a la vez que se plantean causas del crimen, con lo que implícitamente se le justifica, se visibiliza por otro lado «la increíble sangre fría» del asesino, así como el accionar de las autoridades policiales y judiciales.

\section{Conclusiones}

En los medios de comunicación peruanos, en específico en los diarios de circulación nacional, se observa por lo menos dos tendencias: una naturaliza o minimiza los hechos de violencia de género, particularmente a través de la selección léxica y la cita indirecta de los familiares de la víctima o de la mujer violentada, si llega a sobrevivir al ataque; otra tendencia visibiliza y expone los hechos utilizando, además del recurso de la imagen, la selección léxica y la cita directa de los familiares de la víctima o de la mujer violentada si llega a sobrevivir al ataque. 
A diferencia del estudio de Fernández (2003), en el discurso de la prensa peruana caben por lo menos dos posibilidades: la naturalización de la violencia contra la mujer o la visibilización de tal violencia. El tipo de selección léxica y la intertextualidad (uso de la cita directa o indirecta) permiten identificar el tipo de discurso periodístico naturalizador o visibilizador de la violencia contra la mujer.

A propósito de la visibilización de la violencia contra la mujer en algunos discursos periodísticos, sería útil considerar al respecto los planteamientos de Esperanza Bosch y Victoria Ferrer (2012, p. 550), quienes sostienen que «estarían surgiendo nuevos modelos de machismo, que desarrollarían un discurso a menudo paternalista o incluso victimista frente a las mujeres y pondrían en práctica microviolencias o micromachismos (Bonino, 2005). Autores como Lorente (2009) se refieren a estos modelos como posmachismo, y lo caracterizan como aquella estrategia o actitud de ciertos hombres que adoptan una imagen de supuesta sintonía con la igualdad, «marcando incluso distancias respecto al modelo de convivencia patriarcal, pero denuncian hechos puntuales que les permiten lanzar una crítica que asegure su posición social de dominancia».

Por otra parte, respecto del informe emitido en el Perú por el Instituto Nacional de Estadística (INEI, 2014, p. 36) en el que se consideran dos modalidades de feminicidio: íntimo y no íntimo, debo señalar que, en el presente artículo, todos los casos corresponden a la modalidad de feminicidio íntimo, es decir, existe o existió una relación de pareja o expareja entre la víctima y el victimario. En cuanto a la edad promedio de las víctimas, en el informe del INEI (2014, p. 38) el 61,3\% de las víctimas tenía entre 18 a 34 años (2013); en el presente estudio, las edades de las víctimas fluctúan entre los 22 y los 39 años. Respecto de la agresión, se coincide con los resultados obtenidos por el INEI (2014) porque las formas o medios utilizados son diversos: golpes, envenenamiento, acuchillamiento, descuartizamiento; aunque de los ocho casos de violencia presentados, cinco se refirieron a golpes por parte del agresor. En cuanto al lugar de ocurrencia de la agresión, en el informe del INEI (2014, p. 39) se indica que «en el periodo 2009-2013, el lugar de ocurrencia más común del feminicidio es dentro de una vivienda familiar, en este espacio sucede el $56,7 \%$ de los feminicidios»; tendencia que se avala a través de los casos mostrados en la presente investigación: seis de los ocho casos de violencia contra la mujer se produjeron en la vivienda familiar. Respecto del estado conyugal, en el informe del INEl (2014, p. 470) se indica que «el porcentaje de mujeres divorciadas o separadas que fueron víctimas de violencia alcanza el $56,7 \%$ y de las casadas o convivientes, a 32,1\%» (2013); tendencia que no se puede avalar a través de los casos mostrados en la presente 
investigación: seis de los ocho casos de violencia se perpetraron contra mujeres casadas o convivientes, uno contra enamorada y uno contra exconviviente. En cuanto al nivel de educación, no figuró este dato en ninguna de las noticias. Respecto del nivel socioeconómico puede afirmarse que, de los ocho casos presentados, víctimas y victimarios se distribuyen entre las clases bajas, medio-bajas y medias; es decir, como se indica en el informe del INEI (2014, p. 471) «la violencia contra la mujer ocurre en todos los niveles sociales». (En cuanto a un dato inmediato correspondiente a la clase alta, el martes 8 de setiembre de 2015, en «un moderno condominio, situado en una de las zonas más caras y exclusivas de Lima», la abogada Zoila Violeta Salinas Chumacero [38] fue asesinada por su esposo, el artista plástico Carlos Antonio Busso Ezcurra [52]. La noticia se publicó, con mayor o menor detalle, el 10 de setiembre de 2015 en 15 diarios limeños: Correo, Exitosa [de donde se tomó la cita], Expreso, Extra, El Chino, El Comercio, El Men, El Popular, Karibeña, La Razón, La República, Ojo, Perú 21, Trome, Uno).

Así pues, como se señala en la presentación del informe del INEI (2014, p. 5), «pese a los innegables avances de las mujeres sobre todo en educación y trabajo, las diferencias entre ellas y los varones siguen siendo notorias, notables y cuantificables, no solo en sus condiciones de vida, sino también en sus condiciones de muerte. [...] las entidades del Estado deben dirigir sus políticas igualitarias hacia un gran objetivo común: estimular la reasignación social de la carga del trabajo doméstico que oprime a las mujeres y alentar su desarrollo autonómico. Solo así terminaremos con la muerte, la violencia y la explotación que las amenaza». 


\section{REFERENCIAS BIBLIOGRÁFICAS}

Asociación Vida Mujer (2015). No te mueras por mí. Recuperado de http:// www.notemueraspormi.com

Bosch-Fiol, E. y Ferrer-Pérez, V. (2012). Nuevo mapa de los mitos sobre la violencia de género en el siglo XXI. Psicothema, vol. 24, 4, 548-554.

Centro de la Mujer Peruana Flora Tristán. (2005). La violencia contra la mujer: feminicidio en el Perú. Lima: Flora Tristán y Amnistía Internacional.

Fernández Díaz, N. (2003). La violencia sexual y su representación en la prensa. Barcelona: Anthropos.

Fidel, C. y otros. (2014). Mujeres: violencias y sociedad urbana. Buenos Aires: Centro Cultural de la Cooperación Floreal Gorini y Universidad Nacional de Quilmes.

Instituto Nacional de Estadística e Informática (2014). Perú: brechas de género, 2001-2013. Avances hacia la igualdad entre mujeres y hombres. Lima: INEI.

Lorente Acosta, M. (2001). Mi marido me pega lo normal. Agresión a la mujer: realidades y mitos. Barcelona: Ares y Mares.

Nugent, G. (2010). El orden tutelar. Sobre las formas de autoridad en América Latina. Lima: Centro de Estudios y Promoción del Desarrollo y Consejo Latinoamericano de Ciencias Sociales.

Plager, F. (Coord.) (2008). Diccionario integral del español de Argentina. Buenos Aires: Voz Activa.

Ramos Padilla, M. A. (2006). Masculinidades y violencia conyugal. Experiencias de vida de hombres de sectores populares de Lima y Cuzco. Lima: Universidad Peruana Cayetano Heredia.

Real Academia Española (2014). Diccionario de lengua española. Madrid: Espasa Calpe.

Santini, O. (2013). Delito sexual, violencia y desubjetivación. Vínculos saludables para su prevención. Córdoba: Brujas.

Valle Ferrer, D. (2011). Espacios de libertad: mujeres, violencia doméstica y resistencia. Buenos Aires: Espacio. 